\title{
LA MINGA COMO CONSTRUCCIÓN FÍSICA E IMAGINARIA DE SAN GABRIEL
}

\section{THE "MINGA" AS A PHYSICAL AND IMAGINARY CONSTRUCTION OF SAN GABRIEL}

\section{VICENTE ROBALINO C. ${ }^{1}$}

Recibido: 24 de diciembre de 2017 Aceptado: 6 de marzo de 2017

\footnotetext{
${ }^{1}$ Pontificia Universidad Católica del Ecuador, Facultad de Comunicación, Lingüística y Literatura, Quito, Ecuador (vrobalino@puce.edu.ec).
} 



\title{
LA MINGA COMO CONSTRUCCIÓN FÍSICA E IMAGINARIA DE SAN GABRIEL
}

\section{THE "MINGA" AS A PHYSICAL AND IMAGINARY CONSTRUCTION OF SAN GABRIEL}

\author{
VICENTEROBALINOC.
}

PALABRAS CLAVE: minga, relato-testimonio, héroes, heroínas, mitos, ritos, leyendas, progreso, fantasmas, duendes, fiestas, juegos y santos.

KEY WORDS: "minga", storytelling, heroes, heroines, myths, legends, progress, ghosts, elves, parties, games and saints.

\section{RESUMEN}

Este ensayo recoge la visión que los habitantes de San Gabriel (Carchi-Ecuador) han tenido sobre la minga. Esta actividad, símbolo del trabajo y de la solidaridad humanas, se ha convertido, a lo largo de la historia de esta ciudad, en una de las formas más eficaces de reconstrucción física e imaginaria, es decir, de lo moderno, de mitos, ritos, leyendas, juegos que si bien no están directamente unidos al trabajo colectivo de la minga, forman parte de la memoria colectiva.
La minga tiene un origen legendario y constituye por sí misma toda una celebración. En este ensayo, la óptica desde la cual se proyecta la minga es la del relato -testimonio en el que se mezcla lo ficcional con lo real- para darnos una visión múltiple y dialógica de este acontecimiento que identifica a los habitantes de San Gabriel y los hace partícipes de una historia tejida de realidades y de invenciones. 


\section{ABSTRACT}

This research gathers the view that the inhabitants from San Gabriel (Carchi-Ecuador) have had regarding the "minga". This activity -symbol of human work and solidarity- throughout the history of this city has turned into one of the most efficient ways to physically and imaginarily rebuild myths, legends, games which although are not closely related to the collective work of the "minga" are a part of the collective memory.
The "minga" has a legendary origin and constitutes by itself a whole celebration. In this research the manner used to explain the "minga" is storytelling -testimonial in which fiction and real are blended-in order to offer a multiple and dialogical view of this event that identifies the inhabitants of San Gabriel and makes them participants of a story woven with realities and inventions.

\section{LA MINGA COMO CONSTRUCCIÓN FÍSICA E IMAGINA- RIA DE SAN GABRIEL}

\section{A la memoria de mi prima Beatriz}

Como afirma Paul Ricoeur (2000, p. 41): "... no tenemos nada mejor que la memoria para significar que algo tuvo lugar, sucedió, ocurrió antes de que declaremos que nos acordamos de ello". En efecto, en los relatos de los habitantes de San Gabriel, seleccionados para este trabajo, la memoria colectiva juega un papel preponderante, en cuanto permite a los protagonistas de dichos relatos-testimonio, evocar paso a paso cómo se desarrollaron las mingas, quiénes participaron, en qué lugares y qué repercusión social tuvieron. Pues, la minga no solo construye físicamente a un pueblo sino que enriquece su imaginación y reafirma unos valores como la solidaridad, el bien común, resultado de dicho trabajo colectivo. He escogido tres libros (Montúfar, Memoria oral, 100 años de lucha y progreso, cuyo editor es Leopoldo Tobar Salazar; Montúfar, Memoria oral, editado por Oswaldo Cepeda y Recordando leyendas de mi pueblo, editado por Patricia Arcos) y algunos testimonios que, personalmente, he podido recoger para mostrar lo siguiente:

Los relatos-testimonio de los habitantes de San Gabriel en torno a la minga; los mitos y leyendas, como 
el del Duende, que dichos habitantes nos cuentan; e incluir mi propio relato, como testigo, de aquellas historias que en mi infancia escuché en torno a San Gabriel y sus habitantes. Entonces, el primer ámbito de ese ensayo está constituido por los relatos-testimonios sobre las mingas; el segundo, por algunos mitos y leyendas de San Gabriel, que se encuentran en los tres libros citados; y el tercero por mi relato. El hecho de incluir estas tres perspectivas tiene como objetivo el poner en evidencia la porosidad existente entre las fronteras de los géneros: testimonio, historia y ficción y, de esta manera, dar cuenta, de forma más amplia, de las distintas configuraciones ficcionales y no ficcionales que adquiere la memoria colectiva, que comprende todo un universo de sentido, como bien lo expresa Walter Mignolo (2013, p. 85): "... Pensemos, por ejemplo, que nuestras conversaciones familiares o laborales están siempre enmarcadas en una historia familiar o en una historia laboral. Nuestros decires, por lo tanto, se inscriben en esos universos de sentido aunque difusos no menos restrictivos". En efecto, el centro de donde emergen estos relatos-testimonio corresponde al ámbito familiar, es en el tiempo-espacio del hogar de donde brota la memoria colectiva, como se puede apreciar en los relatos de los habitantes de San Gabriel.
De esta manera, el diálogo que dichos textos proponen con el relato oral, la memoria colectiva, el olvido, los silencios y los motivos recurrentes: la minga, los juegos, los mitos, ritos, las fiestas, los santos, etc., expresan todo aquello que un pueblo vivió, imaginó e inventó para recrear su mundo. Es muy singular en estos relatos-testimoniales el afán inquebrantable de cada uno de sus personajes-narradores por construir y alcanzar el progreso. Esta aspiración constituye un fuerte vínculo social; vínculo en torno al cual gira la vida de San Gabriel, pues su gente -la familia- se reúne para alcanzar el bien común y para celebrar ese logro, como la construcción de carreteras, una escuela, una iglesia, un parque, etc.

Como afirma Darío Guevara (1957, p. 22):"Minga quiere decir'reunión de gente invitada para algún trabajo, y mingashca, 'encargado o invitado para una tarea colectiva' y mingani es el verbo que equivale a 'encargar'". En efecto, una de las características que distingue a los habitantes de San Gabriel y de la provincia del Carchi en general es la predisposición para el trabajo colectivo. Pues el entusiasmo por la minga nace -como expresan dichos habitantes en sus relatos- en los distintos barrios: San Pedro, Santa Clara, San José..., cada uno de ellos provistos de un líder encargado de organizar a su gente. Así el Sr. Carlos Hernández nos cuenta de esta solida- 
ria participación del barrio en la minga: "Todo se hacía en base a mingas, todos participábamos en esta actividad, niños y grandes limpiábamos las calles del barrio, y cuando los vecinos hacían su casita los demás también ayudábamos" (Tobar, 2005, p. 109).

Otro aspecto, sin duda importante de la minga, es su carácter legendario, y festivo. Así lo expresa Darío Guevara (1957):

La minga como trabajo de cooperación, como expresión de rito y fiesta, como actividad recreativa y como invitación al disfrute de los bocados nativos y criollos, de la bebida y de la música, en América es tan antigua como las primeras organizaciones de sus pueblos.

La señora Zoila Cadena cuenta en estos relatos- cómo la construcción de la iglesia, por ejemplo, se convierte en un rito celebratorio. Pues los mingueros traían madera "halada por bueyes a los cuales les adornaban sus cuernos con coronas de flores, todos los mingueros tomando su copa, era una fiesta, gritaban ¡VIVA LA MINGA!, las mujeres iban al encuentro, a brindar chicha, aguado, comida, trago..." (Cepeda, 2007, p. 15).

Sin embargo, como afirma María Rosa Crespo, hay que hacer una "doble lectura de la minga":
Hay que hacer una doble lectura de la minga, desde los códigos de gratuidad cuando la minga es funcional a las políticas estatales y, los de reciprocidad, que permiten recuperar la memoria colectiva, la sobrevivencia cotidiana, la identidad colectiva, las reproducciones culturales y la supervivencia del núcleo social. (González, 1991, p. 499)

Si bien la minga, entre los habitantes de San Gabriel, es esencialmente una celebración en torno al trabajo colectivo, el costo social, por ejemplo en la construcción de la carretera Oriental, en 1930, como afirma Luis A. Rosero, citado por Darío Guevara (1957, p. 105), es bastante alto:

Está fuera de toda duda que el cantón Montúfar, después de entregar a la Nación la Carretera Oriental casi terminada, sintió los efectos de una pobreza agobiante. La minga rompió todo bolsillo, dejando a la clase media esclavizada de las casas de retroventa que se llenaron de las prendas de vestir, de bronces, alhajas que pocas o ninguna volvieron... y la gente campesina más deudora del patrón.

Un ejemplo patético de esta pauperización, como resultado de las mingas, es el caso del hacendado Juan Pío V. Guzmán, según nos cuenta la Sra. Luz Ruales: 
Un hombre benefactor de las mingas que se quedó pobre por ayudar, fue Don Pío V. Guzmán, era un hombre alto, entusiasta en esas grandes obras como es la carretera de Duendes, repartía todo de las cosechas de los terrenos que tenía; cuentan que vendió sus propiedades para estas gestas cívicas de los montufareños ... (Tobar, 2005, p. 86)

A pesar que Oscar Efrén Reyes, en su Breve Historia General del Ecuador, afirma que en los años treinta, época en la que San Gabriel construyó la carretera Oriental, el gobierno de Isidro Ayora propició la construcción de carreteras (1949, p. 542), el Sr. Rafael F. Aldás, "dinámico propulsor de la construcción de la
Carretera Oriental", expresa que la construcción de la carretera Oriental es obra que, en su totalidad, corresponde a los habitantes de San Gabriel, pues se conformó el "Comité Pro-Carretera Oriental encargado de la organización total de construcción de esta carretera e inclusive el trazado de esta carretera correspondió a un ciudadano montufareño, el Ing. Rafael Dávila, autor del trazado" (Chaves, 1980, p. 93-94). Mientras que el gobierno de Ayora se encargó de trazar la carretera Occidental, por considerarla prioritaria. Sin embargo, según los relatos de los habitantes de San Gabriel, estos también participaron en la culminación de la carretera Occidental, en los años cincuenta, durante el gobierno de Galo Plaza.

\section{LAS MINGAS, SUS HÉROES Y HEROÍNAS}

La minga no solo sirve para poner de relieve el trabajo colectivo, en la construcción de carreteras, iglesias, parques, etc., sino para la construcción verbal de héroes y heroínas que emergen de una épica, cuyo sueño es el progreso. En efecto, detrás de esa ardua faena que comprende la minga y de su carácter solidario, encaminado a conseguir el bien común, siempre hay representaciones ritual-simbólicas como "el pase de la paloma", que, según una de los narra- doras-protagonistas de estos relatos, se refiere a lo siguiente: "En cuanto a fiestas, mi papacito era el organizador de las mismas, con el pase de las palomas se daba dinero, de una casa hacia la iglesia, con banda, con juegos pirotécnicos, con cantos, con alegría, todos los priostes con sus palomas, el sacerdote recibía el dinero y la paloma la entregaba a otro prioste..." (Tobar, 2005, p. 15). Este dinero servía para los gastos que demandaban la construcción de iglesias. Dentro de 
esta misma representación simbólica, el trabajo sacrificado de la minga hace que surjan héroes y heroínas anónimos, que la narración oral colectiva ha sabido guardar, como el Sr. Pío V. Guzmán, quien, de acuerdo con el testimonio de su hija, lo entregó todo al servicio de la minga:"A mi mamita no le gustaba lo que mi padre hacía, o sea eso de la minga; teníamos un cuarto grande, lleno de todo, mi papacito repartía ..." (Tobar, 2005, p. 5).

En el relato-testimonio "El puente de la muerte"(Arcos, 2013, p. 114-115), en cambio, se hace una crítica, al profesional que construyó un puente "para unir la carretera Pizán con la Gruta" de la Paz, en el sentido que dicho profesional no invirtió todo el material destinado para la construcción del mencionado puente: "Edgar miente al decir que esta es su mejor obra ya que se robó la mitad del dinero que se iba a invertir en el puente. El pueblo enfurecido, sin pensarlo dos veces, arrojó a Edgar desde lo alto del puente hacia el río ..." (Arcos, 2013, p. 115). Sin embargo, el alma de Edgar tomó venganza y a todas las personas que cruzaban el puente se les presentaba como "un enorme gato negro y de ojos brillosos". Solo cuando fue construido y bendecido el puente, aquel temible gato negro desapareció.

Otro relato-testimonio relacionado con las mingas es el llamado "Iglesia". Se trata de la existencia de una presencia siniestra que impide que lo construido un día -una iglesia-, en la noche sea destruido. Esta presencia siniestra está representada por un temible toro: "Ellos se armaron muy bien de piedras y palos y se escondieron; al llegar la media noche lograron ver que alguien muy rápido corría hacia ellos, más y más cerca, cuando miraron era un toro muy grande, de color negro ..." (Arcos, 2013, p. 65).

Así vemos en estos relatos cómo la minga no se reduce al trabajo mecánico, el de cumplir con una determinada tarea, sino que, por el contrario, es toda celebración colectiva, una fiesta, un misterio que revelar, un asombro, en la que la participación de la mujer es muy importante: "La que incentivaba a las primeras mingas era la señora Juana Calvache, esposa de don Pablo Rosero, se hacía los mítines los lunes y los sábados se desfilaba por las calles con el grito ¡A la carretera ya me voy a trabajar!" (Tobar, 2005, p. 89). Este heroísmo muchas veces se convierte en un sacrificio, como el traer madera de las montañas o el entregar la propia vida. Este hecho verdaderamente heroico se cuenta en uno de los relatos: "En el sector de Cúnquer era feo para trabajar, era pura peña, me acuerdo que un hombrecito de Bolívar estaba trabajando y rato menos pensado se fue peñasco adentro [...]" (Tobar, 2005, p. 57). 


\section{RELATO}

El interés que tienen para mí estos relatos-testimonio proviene, sobre todo, del hecho de haber escuchado en mi infancia, de los labios de mis padres, mis tías y mis abuelos, algunas historias y de haber conocido a varios personajes de quienes se habla en ellos. De ahí que cada vez que visito San Gabriel y camino por sus veredas siento que estoy despertando a mis muertos para -entre el asombro y la lluvia- volver a escucharlos. Así conocí la leyenda de "La Virgen de las Nieves", el cuento de "La Vieja del Monte", la aparición de "El Duende en las zanjas", el deambular de las almas por los zaguanes... Asimismo participé en una minga y en algunos de los juegos que se mencionan en dichos relatos: las escondidas, los trompos, aunque por mi temperamento yo prefería escuchar a mi tía, en las noches tremendamente oscuras, indescifrables, sus versiones -no exentas de imaginación- de sus lecturas: Los Miserables, de Víctor Hugo, El Conde de Montecristo de Alejandro Dumas, el poema "Los motivos del lobo" de Rubén Darío, María de Jorge Isaacs, entre muchas otras.

Uno de los primeros recuerdos que conservo de San Gabriel es el de la iglesia con su ángel -San Gabriel, su- pongo- en actitud de vuelo y su campanario en el que, según me contaban mi tía y mi abuela, pernoctaban unas temibles lechuzas que se alimentaban de cadáveres y ratones, cuya mirada era como la de la gata, Paca, que dormía junto a la hornilla, en la casa de mis abuelos, donde transcurrió mi infancia. El cuerpo de este animal, que jamás pudo concebir mi imaginación, era igual al de un ave. Por cierto, yo nunca vi a tan extraña ave-felino; sin embargo, contaban que una vez todo el pueblo se alarmó porque vio en pleno día a una Lechuza: todos pensaron que era la señal de algún suceso trágico. También participé en la reconstrucción de la iglesia. Recuerdo que a mis ocho años formé parte de una cadena humana que transportaba baldosas desde un camión hasta la iglesia. Asimismo recuerdo que la minga estaba acompañada por una banda y que unas señoras repartían chicha a los mingueros. Lo que percibía en esta minga no eran los entretelones políticos, que un proyecto de trabajo colectivo puede tener, sino el afán colaborativo y de entusiasmo -no sé si llamarlo patriotismoque cada barrio de San Gabriel poseía, como su patrimonio. 


\section{LAS MINGAS Y EL RELATO-TESTIMONIO}

Si bien, en primer término, el relato-testimonio posee, como lo afirma Renato Prada Oropeza, un carácter marcadamente referencial; luego, el narrador-protagonista de dicho relato disfruta de una amplia libertad expresiva e imaginativa que conduce al universo de la ficción. De ahí que en los relatos-testimonio de los habitantes de San Gabriel, el lector transite desde una fuente referencial hacia un universo de la narración ficticia, que si bien no existe en toda su plenitud, como en el cuento o la novela tradicionales (canónicos), el carácter reiterativo de unos mismos acontecimientos conduce al lector a no aceptarlos como reales, sino a dotarles de cierto matiz imaginario-ficcional.

Así sucede, por ejemplo, con el tema de la minga que, al ser narrado desde tantas perspectivas, y confrontado con tantas versiones, pierde su primera fuerza referencial para entrar en el espacio probabilístico de lo imaginario, de aquello que ocurrió pero en la nebulosa del tiempo del cual emerge, no como realidad sucedida sino como aspiración evocadora: "Como no teníamos radio ni televisión se dormía breve: mi papacito leía el periódico El Debate, que valía un real y medio, nos mandaba a comprar donde Don Ezequiel Landázuri" (Cepeda, 2007, p. 18). Es sorpren- dente notar cómo en este fragmento la referencialidad textual queda desplazada para dar paso a la autorreferencialidad, al relato que parece contarse a sí mismo, sin necesidad de estar recurriendo a la tiranía de la referencia. Me parece que uno de los grandes méritos que poseen estos relatos -sin proponérselo- es aquel natural tránsito que se da, de la mera referencialidad hacia la evocación-ficcional, recurriendo a la magia del lenguaje, o sea al territorio de las connotaciones, pues este "se dormía breve", es una expresión que, en su ambigüedad semántica, nos lleva a las "imprecisiones" de lo metafórico, a la sugerencia. Sin embargo, no solo es el lenguaje, en su plenitud sugestiva, el que moldea la figuratividad textual sino el tiempo con su poder evocativo el que va configurando planos ficcionales, en los que memoria y olvido crean correspondencias al servicio de lo narrado, como en este ejemplo: "Cuando yo vine a trabajar en esta hacienda, el bosque de arrayanes era una maravilla..." (Tobar, 2005, p. 117). Todos estos relatos juegan con la ambigüedad temporal, pues la percepción de lo sucedido se entiende como envuelta en una nubosidad: "Mi papá era alfarero, nosotros trabajábamos con el barro, toda la vida la pasábamos haciendo ollas..." (Tobar, 2005, p. 
114). “En ese tiempo hacíamos las bolas de barro, las cachas eran más grandecitas..." (Cepeda, 2007, p. 121). "El parque era una especie de bosque, había ya el andén al ruedo, lo demás eran árboles, un perfecto bosque..." (Cepeda, 2007). Sabemos que sucedió tal o cual hecho, pero ignoramos cuándo: "Toda la vida...", "En ese tiempo", "El parque era...". Así, al tiempo se lo despoja de su corteza cronológico-referencial para convertirlo en alusión metafórica, rescatada de las garras del olvido, petrificada en la memoria de los habitantes de San Gabriel.

\section{LAS MINGAS, LOS FANTASMAS Y EL MAL}

De acuerdo con estos relatos, los habitantes de San Gabriel no solo buscan de manera infatigable al fantasma del progreso, sino que se reúnen en las noches -en esas noches rotundas- para reinventar otros fantasmas, aquellos que han atravesado siglos, como "la vieja del monte". Pero cómo concibe la imaginación colectiva a la vieja del monte: "En el terreno que tenía mi papá por ahí en el Chicho, nos decía andarán con cuidado porque por ahí se asoma la vieja del monte que está peinándose. Recuerdo que a mi hermano Uben, menor que mí, cuando estaba en la escuela murió porque le había comido el corazón la vieja del monte" (Tobar, 2005, p. 59).

Otro de los personajes nocturnos, cuya presencia causa espanto, es "la viuda", quien, al igual que la vieja del monte, deambula por el campo. Se trata de una mujer que en su vida diurna tiene un nombre y apellido, por ejemplo, Margarita Fuentala, en la noche se transfigura en una calavera y camina en el aire: "... había sido calavera y caminaba en el aire, no tenía pies, después de esto comenzaron a aullar los perros..." (Cepeda, 2007, p. 23). Asimismo "El Duende" es una figura fantasmal que deambula por el campo, concretamente habita en las quebradas. Don Antonio Huera nos cuenta que él vio al Duende, en la madrugada, "que estaba vestido de blanco". Sin embargo, la imagen de El Duende que yo tenía en la infancia era la de un niño menudo, con un enorme sombrero; no recuerdo bien si se le atribuía a este ser el hecho de robarse a los niños o producirles al menos algún daño, de ahí que en mi pueblo -San Gabriel- de tal o cual persona se decía que "estaba enduendada". En los relatos recopilados por los estudiantes del colegio Técnico Agropecuario Jorge Martínez Acosta y editados por la profesora Patricia Arcos, el mito del duende tiene estas variantes: ya no es el "duende" sino "la Duenda", quien embruja 
a sus víctimas, posee "colmillos". Aunque, en todos los casos, el duende o la duenda posee una figura pequeñita -mide 80 centímetros-, usa sombrero grande, vive en las zanjas y quebradas.

\section{LAS MINGAS, LAS FIESTAS, LOS JUEGOS Y LOS SANTOS}

San Gabriel, como todo pueblo que se siente vivo, tiene sus celebraciones que las comparte con las de otros pueblos andinos y las de otras regiones, como la fiesta de los Santos Inocentes que se celebra los primeros días de enero. Escuchemos a nuestra narradora, Dorita Jiménez: "El baile de los inocentes era la costumbre de disfrazarse por grupos, salir a la calle y recorrer el pueblo pidiendo colaboración, cuando la organización era muy buena, se hacía por sectores y los Inocentes más nombrados eran los del Arrayán, los del barrio de Santa Clara, barrio Santa Rosa" (Cepeda, 2007, p. 117). Además de esta festividad, los narradores de estos relatos mencionan la fiesta del Corpus Cristi, los Sanjuanes y las fiestas dedicas a "San Pedrito" en la parroquia de Cristóbal Colón (Caico), cercana a San Gabriel. A este santo se lo presenta entre dos esferas de acción antitéticas: la de la bondad y generosidad, pues ayuda a que los latifundios del hacendado prosperen, y la del Santo castigador, que envía grandes males, como la ceguera y la cojera.

Con respecto a los juegos, se pueden considerar, según estos relatos, los siguientes: las corridas de toros, el juego de la guerra, la pelota de guante, entre otros. De estos juegos destaca, por su peculiaridad, el segundo. El juego de la guerra, en el que participaba mi padre como líder, se realizaba de esta manera, según nos cuenta la Sra. Mercedes Landázuri: "En el río se daba una matita de payaca; los jóvenes se hacían dos grupos, de un lado era Aníbal Robalino era el jefe y de la nuestra Luis Alberto... Aníbal Robalino se posesionaba del bosque de las Señoritas Valdospinos y en nuestra cuadra Luis Alberto comenzaba la guerra..." (Tobar, 2005, p. 74). Lo importante de este juego es que representaba las guerras "reales" que se daban entre conservadores y liberales; en otras ocasiones estos juegos tenían un carácter premonitorio, pues anunciaban lo que iba a suceder.

De esta manera podemos apreciar lo que destacan estos relatos es el tránsito de lo testimonial a lo ficcional y las modificaciones a los que están sometidos, debido a su carácter eminentemente oral. Su riqueza narrativa se encuentra, básicamente, en los mitos, ritos 
y símbolos que representan a toda una colectividad.

Sin duda, la minga ha sido la actividad de mayor importancia para los habitantes de San Gabriel, pues se conserva el recuerdo de este trabajo. Sin embargo en la actualidad, según algunos de los narradores de estos relatos, esta legendaria tradición se está perdiendo.

Del carácter testimonial de estos relatos emerge la división de grupos so- ciales y la lucha por la propiedad de la tierra, los hacendados y el pueblo. Los primeros se unieron para la realización de esta gran obra, la construcción de la carretera Oriental. Sin embargo, como bien testimonia Luis A. Rosero, citado por Darío Guevara (1957, p. 105): "Está fuera de toda duda que el cantón Montúfar, después de entregar a la nación la carretera Oriental casi terminada, sintió los efectos de una pobreza agobiante". 


\section{BIBLIOGRAFÍA}

Arcos, P. editora (2013). Recordando leyendas de mi pueblo. Tulcán: Casa de la Cultura Benjamín Carrión, Núcleo del Carchi.

Cepeda, O. editor (2007). Montúfar, memoria oral. Montúfar.

Chaves, V. (1980). San Gabriel y la gruta de La Paz, Quito.

González Aguirre, I. (1991). VI Encuentro de historia y realidad económica y social del Ecuador y América latina (13-18 noviembre 1989). Cuenca: Universidad de Cuenca.

Guevara, D. (1957). Las mingas en el Ecuador, orígenes, tránsito, supervivencia. Quito: Editorial Universitaria.
Mignolo, W. (2013). De la hermenéutica y la semiosis colonial al pensar descolonial, Quito: Abya-Yala.

Prado Oropeza, R. (2001). El discurso-testimonio y otros ensayos. México: UNAM.

Reyes, O. E. (1949). Breve Historia General del Ecuador. Quito: Talleres Gráficos Nacionales.

Ricoeur, P. (2000). La memoria, la historia, el olvido. México: FCE.

Tobar Salazar, L. editor (2005), Historia oral del Cantón Montúfar. Montúfar. 